\title{
Finance Policy for Public Health Disease Prevention: Addressing the Number One Cause of Death in the Western World
}

\author{
R. Philip Eaton ${ }^{1}$, Christine Trujillo² ${ }^{2}$ David S. Schade ${ }^{\text {* }}$ \\ ${ }^{1}$ Division of Endocrinology, Department of Internal Medicine, University of New Mexico Health Sciences Center, Albuquerque, \\ New Mexico, USA \\ ${ }^{2}$ House of Representatives, State of New Mexico, New Mexico, USA \\ Email: *dschade@salud.unm.edu
}

How to cite this paper: Philip Eaton, R., Trujillo, C. and Schade, D.S. (2021) Finance Policy for Public Health Disease Prevention: Addressing the Number One Cause of Death in the Western World. World Journal of Cardiovascular Diseases, 11, 553-563. https://doi.org/10.4236/wjcd.2021.1112052

Received: August 10, 2021

Accepted: December 6, 2021

Published: December 9, 2021

Copyright $\odot 2021$ by author(s) and Scientific Research Publishing Inc. This work is licensed under the Creative Commons Attribution International License (CC BY 4.0).

http://creativecommons.org/licenses/by/4.0/ (c) (i) Open Access

\begin{abstract}
Background: The lack of a finance policy to cover heart coronary artery disease CT imaging led to an epidemic of heart disease, the most common cause of death in the United States. The difficulty for many adults to pay $\$ 150$ for CT heart imaging was the impetus for public health reform through legislative intervention. Methods: The key to finance policy reform was the organization of the medical environment involved in asymptomatic heart disease. Using the ecosystem paradigm for organizational alignment, the legislative goal was financing the $\$ 150$ heart image to identify and medically prevent symptomatic heart disease, obviating future surgical costs of $>\$ 100,000$. Results: Assisted by stakeholders for public health reform, a 3-year initiative to pass a legislative bill mandating health insurance coverage of $\$ 150$ heart imaging was signed into law. Understanding the legislative process was necessary for successful advancement of public health and eliminating unnecessary costs of an established conservative ecosystem. Conclusions: Texas was the first state to achieve this legislative goal and New Mexico soon followed. If political environments, regardless of country following this road map of public health reform, a significant beneficial impact upon heart disease, its cost, and healthier public would result.
\end{abstract}

\section{Keywords}

Health Care Reform, Ecosystem, Legislation, Calcium Heart Scan, Heart Disease

\section{Introduction}

The objective of this work is to assist other stake holders interested in preventing 
atherosclerotic heart disease with a guideline for interacting with their state legislature. Since only Texas and New Mexico have approved legislation to mandate insurance companies to reimburse coronary artery calcium scanning CT to prevent heart disease, a step-by-step approach should be extremely helpful. In the last decade, the lack of a finance policy to address patient costs of diagnostic imaging technology, has led to unrecognized and untreated progression of heart disease in the western world, and the most common cause of death in the United States. Widespread early diagnosis has not occurred in part because of an unanticipated patient reluctance and inability to pay for disease identification using this coronary artery disease (CAD) imaging breakthrough technology. To correct this silent epidemic of unrecognized CAD, a legislative funding solution for public health reform was sought. The goal was to finance a $\$ 150$ heart image by computed technology (CT), to identify and medically reverse heart disease, and to remove the need for downstream $\$ 100,000$ costs in surgical vessel repair. An ultimate outcome will also be a healthier and more productive adult population.

While seeking a political resolution to a public health issue that may be appropriate, achieving passage of a legislative bill by any legislative process is a long and difficult undertaking. It requires knowledge of the intricacies of legislative procedures (some logical, some not) that were developed over many years and understood by few individuals outside of the legislators and lobbyists involved with bill passage. Members of the health profession may be in uniquely informed position regarding both public health \& disease management to pursue political support for such legislation. This article uses the passage of a coronary artery calcium (CT) bill by the State of New Mexico to illustrate our legislative process appropriate for all states to address this massive loss of life. It began by proposing a mandate for patient health insurance to cover the $\$ 150$ cost of the initial imaging diagnosis of early asymptomatic CAD.

This imaging technology can recognize early asymptomatic coronary artery disease that is based upon CT scanning of heart calcium [1]. Healthy, asymptomatic patients with heart disease can be identified by $\mathrm{CT}$ imaging and can be promptly medically treated. For less than 50 cents/day, these asymptomatic patients with CT quantified disease can be prevented from progressing to the symptomatic phase leading to death by heart attack or stroke [2]. The key to the finance policy is the recognition by one medical organizational environment involved in treatment of asymptomatic $\mathrm{CAD}$, and a second involved in treating symptomatic CAD. Defined as differing ecosystems derived from the natural world, this paradigm clarifies the economics and interdependence of these two institutionalized elements for successfully eliminating the silent epidemic of CAD.

This spontaneous alignment of different providers of complementary expertise within each ecosystem creates an organizational environment for successful clinical outcomes. Borrowed from the business world of innovation this paradigm is applied here to the management of coronary artery disease [3] [4]. This 
public health epidemic results from a failure to identify and reverse asymptomatic disease. From a management perspective, the ecosystem for asymptomatic cardiovascular disease has a CT diagnostic cost of $\$ 150$, distinctly different from the emergency surgical intervention cost range of $\$ 30,000$ to $\$ 200,000$ of the ecosystem of symptomatic cardiovascular disease as shown in Figure 1. Both ecosystems have similar annual follow-up costs in the $\$ 400$ dollar range unless the symptomatic ecosystem patient requires additional invasive procedures. If the appropriate initial treatment of asymptomatic disease prevents symptomatic disease, cardiovascular disease (heart attacks and strokes) could be significantly reduced. This would remove cardiovascular disease from being the number one cause of death in the United States, and significantly reduce the current annual medical cost to this country of 350 billion dollars [5] [6] [7].

The CT identified calcium in the heart arteries establishes atherosclerosis (e.g., plaques in the coronary arteries) and is quantified in Agatston units, so that the coronary artery calcium score is a definitive heart assessment in asymptomatic patients. Scanning scores of zero predict a near absence of atherosclerosis, with a minimal risk for having a heart attack [8] [9]. With increasing scores of 100 units, 200 units, etc., a positive statistical correlation with having a heart attack within 5 years per 100-unit increments informs the patient that treatment with medications should be started immediately to prevent advancing to the symptomatic state [10]. The American College of Cardiology/ American Heart Association and the European Society of Cardiology issued guidelines recommending the use of CT calcium scoring to guide the medical intervention in patients at intermediate risk for cardiovascular disease [11] [12]. The possibility of this technology interrupting progression to symptomatic life-threatening coronary artery disease and invasive hospital-based treatment has become reality [13]. Others have suggested that this technology should be a routine health procedure in all individuals over the age of 50 years [2].

\section{CT Treatment History}

During the years following 2000 onward, the medical literature became replete with enthusiasm for routine screening to diagnose early coronary artery atherosclerosis with calcium CT and to treat aggressively with medical management [14]. However, as reported by the American Heart Association, there has been no significant reduction in death from CAD during the last 10 years, nor any reduction in the 350-billion dollar expense for cardiovascular disease [6]. In fact, the American Heart Association's special panel predicts that this cost will triple within the next decade [6]. One conclusion of this dilemma was the difficulty for the patient to pay for the $\$ 150 \mathrm{CT}$ calcium scan cost. Even with medical insurance, this cost has been non-reimbursable. In addition, there was little enthusiasm by the symptomatic health care ecosystem for reducing the incidence of cardiovascular disease. In 2012, physicians in Texas began following the outcome 


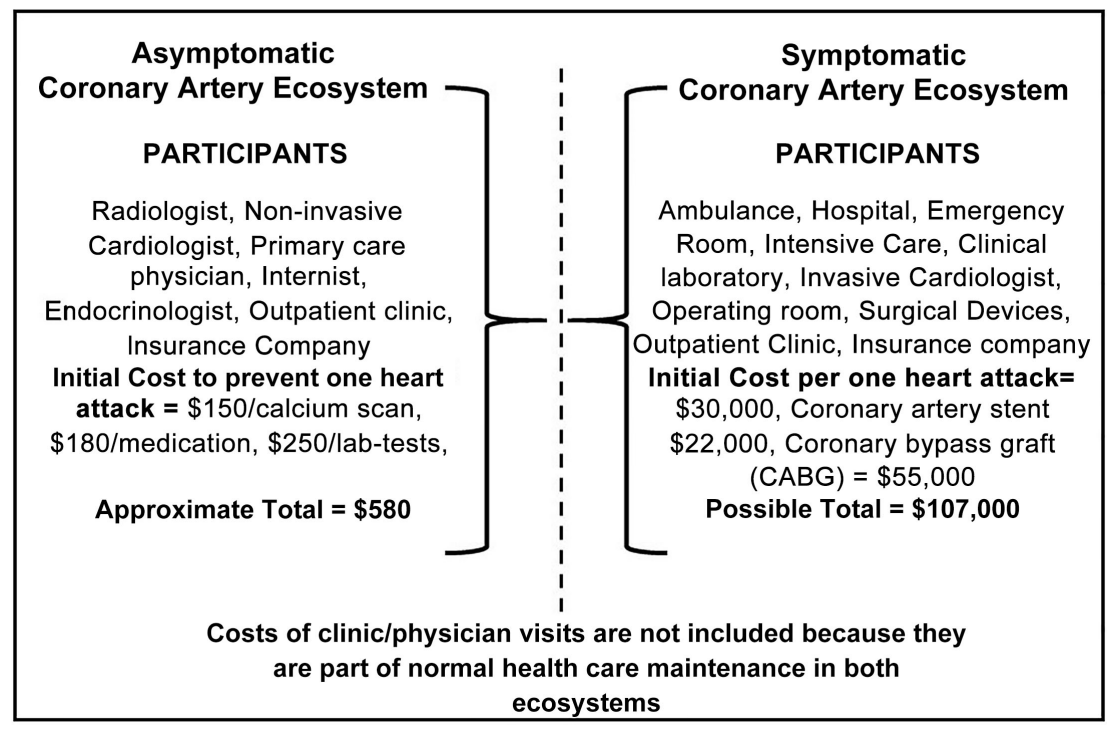

Figure 1. Two sequential healthcare ecosystems of coronary artery disease-patients enter pre-clinical diagnosis of Asymptomatic CAD through the left ecosystem where detecting the presence of vessel plaque with Coronary Calcium Scan is quantified. Elevated levels of plaque are treated for reversal with Statin type medications to prevent progression to Symptomatic CAD. Clinical presence of CAD symptoms requires referring the patient on to the right symptomatic ecosystem for the addition of interventional cardiology/radiology treatment to avoid an imminent or active heart attack. The total \& initial annual healthcare costs of the two ecosystems are significantly different [4].

of medically treating Agatston positive patients after they had obtained Legislative mandated insurance coverage for CAC [15]. Their data suggested an association between patient outcome after passing the legislation mandating insurance coverage for CAC scans, and the decline in incidence of cardiovascular disease.

\section{The Challenge of Financing the Break-Through Technology}

If removing the cost of a CT calcium scan for patients by legislation leads to primary care physicians initiating early medical reversal of atherosclerosis, this would represent an appropriate partnership of government with the asymptomatic coronary ecosystem. Parenthetically, it is common for "Executive Health" programs across the country to include the calcium heart CT as a matter of health-outcome policy. To achieve this public health reform, significant participation by all 50 states in the United States would be needed [16]. The process of enlisting the support of state legislatures to consider a calcium heart CT bill begins by engaging the politics of healthcare legislation as described below.

\section{Drafting the State-Specific Legislative Bill}

Country and/or State specific acceptance of Public Health reform needs leadership, encouragement, and support by legislators and credible stakeholders to become reality. In the United States, pursuing state legislation for insurance 
coverage of coronary artery CT begins by reviewing a bill that has already been passed by a state legislature and signed by the state governor. Physicians in New Mexico began with HB 1290 passed by the Texas legislature in 2009. This bill became publicly available to facilitate a conversation with the physician leadership and others involved in state politics [14]. However, each state will have unique legislation processes and procedures needed to tailor the approach toward local requirements and expectations. With a draft in hand, obtaining consideration by legislators is usually initiated by presenting the bill as a proposal for the state's Health \& Human Services Committee. The purpose of this meeting is to seek legislator support and to identify a House or Senate member to "Carry the Bill" in the anticipated legislative committee \& floor sessions. That individual will utilize local procedures to obtain attorney and staff consultation to revise the document in accordance with state laws and to create a title for the bill for consideration by the legislature.

\section{Message-Specific Rationalization of the Legislative Bill}

The next step is to create a state-specific message that is used for both brief explanations of the expectations of the legislation, as well as to provide printed material, handouts, and press releases to begin enlisting public and institutional support. The core message begins with health reform to save lives and/or save money, depending upon the targeted audience. In addition, a handout visualization of a normal and diseased coronary artery calcium scan is invaluable for the goal of convincing legislators and influential individuals. An example of an asymptomatic but diseased "positive" CT in such a handout is shown in Figure 2.

This effort will require a Stakeholder-eco Team for Public Health \& Finance Policy, which is a mirror image of the interests of the legislature. This team represents interests of all involved organizations, public bodies, interest groups, and state and community governmental leaders in addition to legislators and their support systems regarding public health reform. Typical membership of this type of team is shown in Figure 3, which is necessary to address the perspective of all the members of the legislature. In this process, an important management financial opportunity was identified. If this bill proposes a mandate that each health insurance company cover the $\$ 150$ cost of the heart calcium scan, then the legislature would not be adding a New Mexico "appropriation" coming from state financing. This means that the bill would not need to be additionally presented to the Senate Appropriation Committee and compete with the challenging competition of funding for all other monies appropriated for schools, hospitals, roads, etc. It also was recognized as positively balancing the bottom line of the insurance industry, which would be comparing expenses of prevention to that of emergency surgical treatment. These observations were critical to the possibility of the bill passing and being acceptable to the governor pertaining to finance policy and health reform. 


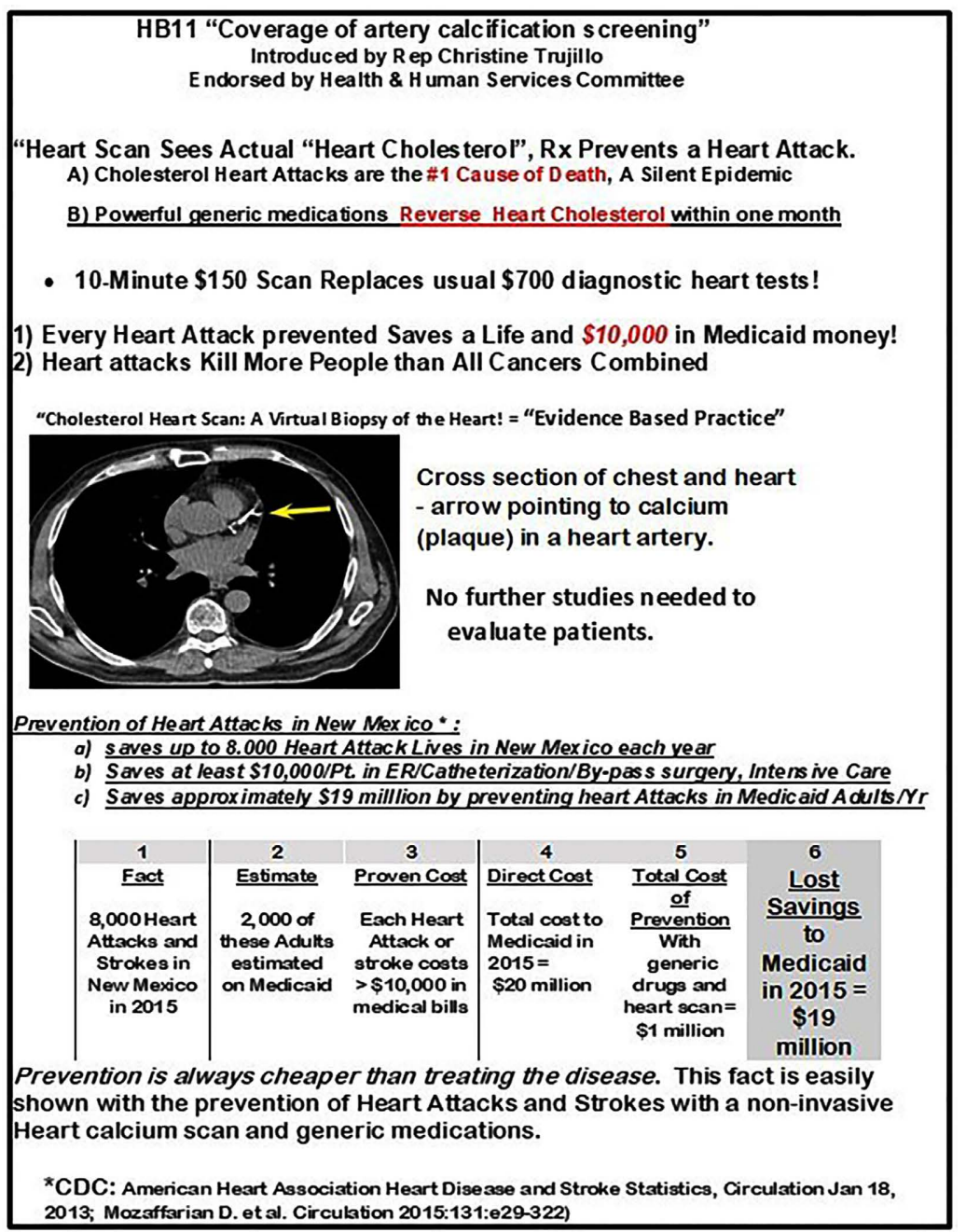

Figure 2. Visual explanation of the benefits of a bill for legislative health reform typical handout of impact of health insurance coverage of artery calcium imaging to inform stakeholders and legislators of the value of detecting early asymptomatic coronary heart disease (CHD). Goal is urging legislators to vote a "Do Pass" on a bill under committee or house/senate floor consideration.

\begin{tabular}{|c|c|c|}
\hline \multicolumn{3}{|c|}{ Stakeholder Ecosystem Team } \\
\hline Care Givers & Administrators & Business Reps \\
\hline Primary Care Physicians & Medical School Deans & Health Insurance \\
\hline Endocrinologists & Public Health Officials & $\begin{array}{l}\text { Co. Attorneys } \\
\text { Community }\end{array}$ \\
\hline Cardiologists & Health Care & Leaders \\
\hline Physician Assistants & Policy Managers & Lobbyists \\
\hline Radiologists & Hospital/clinic & Health Service \\
\hline Clinical Lab Directors & administrators & Consultants \\
\hline Nurse Practitioners & CEOs & \\
\hline
\end{tabular}

Figure 3. Stakeholder ecosystem-team supporting Public Health \& Finance Policy. Three groups of credible community leaders who are critical to educating legislators of the value and importance of the legislative bill being proposed to save lives and money with public health reform. 
The involvement of the team members will be significant at every step in the legislative process as the pros and cons of the stakeholders are brought into the discussions. Importantly, how the legislation will benefit individual members of both legislators \& stakeholders is important. Understanding that all stakeholders may be asymptomatic but CT positive for calcium-containing coronary plaques is important. Explaining how the bill will benefit each legislator and his/her family will often move a bill forward when confusion of the bill's importance occurs.

\section{Final Steps in Obtaining Legislature Bill Approval for CT Heart Scanning}

With the members of the Stakeholder-eco-team employing the facts supporting the prevention of heart disease with early coronary artery CT testing, it is critical to interact one-on-one with every representative and senator of the state as each has a vote in a committee and/or on the floor of the House or Senate. At the same time, the Stakeholder-eco-team should meet with the individuals in the fiscal evaluation offices of the legislature who will independently present their fiscal implications to the legislature. Having done this, the legislator carrying the bill, and supported by members of the stakeholder eco-team, will need to present the bill to committees of the House of Representatives and by separate committees of the Senate. Depending upon the individual state rules, after two or more committees have passed the bill, it must be sent to the floor for a vote by the entire House and Senate, respectively. In parallel with these interactions, it is important to have interacted both casually and formally with the Governor and members of the Governor's staff. They, in turn, will be engaging casually with legislators concerning the value of this legislation for their constituents and to the public health \& finance policy of the state [17].

If the bill receives a "do-pass" from both houses, it will be sent to the Majority Leader of the senate for consideration to move it forward for approval and signature by the Governor of the State. The amount of time required for this process will differ for each state, depending upon how often and how long per year the legislature is in session, the volume of the legislative business that is being addressed, and the effectiveness of the stakeholder-eco-team and legislator who are carrying the bill. A few states have initiated this process following the success of the Texas Legislature, and the legislature of New Mexico passed the coronary artery calcium bill in January 2020. It was subsequently signed by the governor and became law in New Mexico after a long three-year process.

\section{Outcome Possibilities of a Legislative Bill}

It is common or even usual for a legislative bill to require more than one legislative session to achieve a "Do-Pass" response. A recommendation for revisions, deletions, and additions should be anticipated. Similarly, there is no guarantee that the Governor will pass a bill sent from the legislature. The Governor may respond with a veto with or without suggestions for revising the bill for later 
consideration. An example of this type of veto with suggested revisions is given in Figure 4. Any changes that need to be made in the bill will result in starting back at the beginning of the entire legislative process, at a later legislative session. All members of the stakeholder-eco-team desiring an eventual successful outcome will require commitment, patience, and perseverance.

\section{Conclusions}

The legislative solution of mandated personal insurance coverage for the heart calcium scan provided a finance policy of state legislation to enable health reform for heart attack prevention. The result is a demonstration of legislative action to impact critical public health outcomes, as influenced by informed stakeholders. Both the legislators and the leaders of the two heart ecosystems (symptomatic and asymptomatic), quickly understood the relational environments to both healthcare outcomes of cost and clinical patient survival. It was also apparent to health providers and to their patients that this perspective might realistically address the number one cause of death in the United States i.e., cardiovascular disease. The documentation validates $\&$ justifies the lengthy and intricate process that led to an achievement to advance public health and decrease health costs by the final approval by a state government (Figure 5).

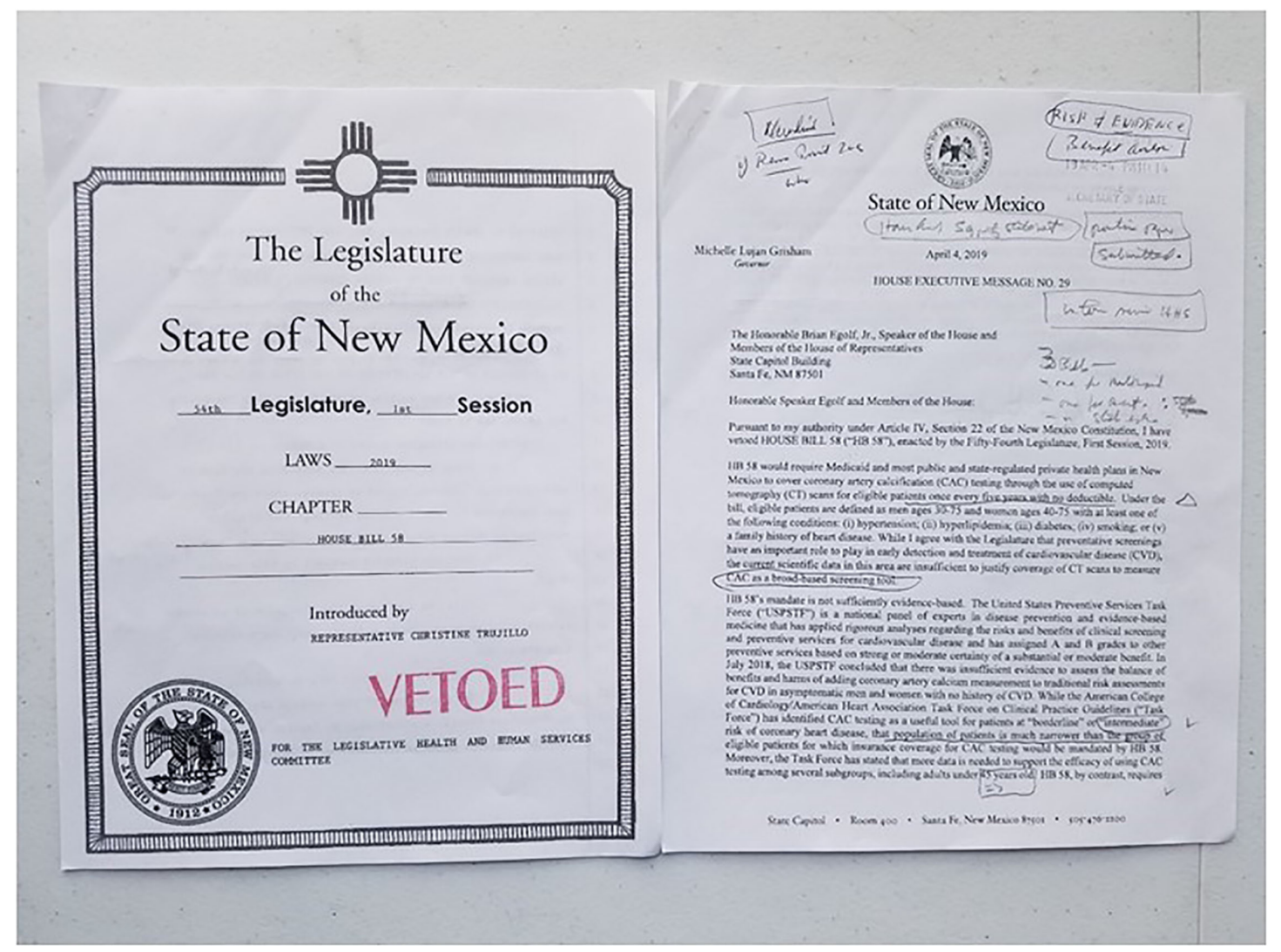

Figure 4. The vetoed legislative bill and reasons for rejection. The important outcome of a governor's veto is understanding the focus of the required bill's revision and clarifying the changes made to the office of the governor prior to re-submitting an improved bill at the next year's session. 
Legislative Affairs

Office of Govemor Michelle Lujan Grisham

490 Old Santa Fe Trail | Room 400

Santa Fe, New Mexico 87501

Legislative Request Form

$55^{\text {th }}$ Legislature, First Session of 2020

Proposal Summary

\begin{tabular}{|c|c|c|}
\hline Title & \multicolumn{2}{|c|}{ Heart Artery Cakium Scan } \\
\hline Bill Priority & \multicolumn{2}{|c|}{ High } \\
\hline $\begin{array}{l}\text { Is this a reintroduction from } \\
\text { a previous year? }\end{array}$ & \multicolumn{2}{|l|}{ QYES $\square \mathrm{NO}$} \\
\hline \multicolumn{2}{|c|}{ If yes, please provide years previously introduced. } & $\begin{array}{l}\text { Enter years previously introduced. } \\
\text { HB11/2017; HB58/2019 }\end{array}$ \\
\hline \multicolumn{3}{|c|}{$\begin{array}{l}\text { Applicable Statute(s): } \\
\text { (only new sections to } 6 \text { named statutes are created) }\end{array}$} \\
\hline \multicolumn{3}{|c|}{$\begin{array}{l}\text { If the proposal amends existing statute(s), provide the relevant citation(s). If the proposal would create a new } \\
\text { section of statute, leave blank. }\end{array}$} \\
\hline \multicolumn{3}{|l|}{ Bill Summary } \\
\hline \multicolumn{3}{|c|}{$\begin{array}{l}\text { This bill removes the } \$ 150 \text { cost barrier to prevention of heart attacks to adults who are } \\
\text { unaware they have silent cholesterol artery disease that can suddenly rupture and cause a } \\
\text { massive heart attack. It is a revision of HB58, improved by responding to the concerns } \\
\text { expressed by Governor Grisham in the House Executive Message No. } 29 \text { as follows: } \\
\text { The bill requires insurance to cover the } \$ 150 \text { cost not subject to a deductible, of a heart } \\
\text { artery Calcium Scan which quantitates artery cholesterol build-up that causes a heart attack. } \\
\text { Eligible enrollees are ages } 45-65 y r \text {, who demonstrate "intermediate" Risk for heart disease } \\
\text { by a health provider determined by an evidence based algorithm widely used in the medical } \\
\text { community. The health coverage is limited to provision of a single heart artery scan that can } \\
\text { only be repeated once in five years if enrollee has a negative initial scan with no evidence of } \\
\text { cholesterol disease. Any further cardiac testing or procedures are at the discretion of the } \\
\text { insurance provider to offer or refuse coverage or as required by law. These provisions shall } \\
\text { not apply to policies for short-term travel, accident-only or limited or specified disease } \\
\text { policies, or plans or certificates of health insurance. The eligible enrollee also agrees to } \\
\text { follow heart disease prevention guidelines designed to educate the public regarding cardiac } \\
\text { care to reduce disability and deaths due to heart disease and stroke. }\end{array}$} \\
\hline
\end{tabular}

Figure 5. An official legislative-bill request form. Following three years of daily interactions with legislators, stakeholders, community leaders, and state government offices, a successful request led to approval by the legislature and signed by the State of New Mexico Governor, the Honorable Michelle Lujan Grisham. The bill mandated all medical insurance companies to cover the cost of a coronary artery calcium scan with no personal deductions. Every step identified with much formal and informal effort by the Stakeholder ecosystem team was essential to the successful outcome.

If the political environments of all 50 states and of western countries were to follow this public health reform, a significant positive impact upon Population health and upon the number one cause of death in the United States and its cost might be accomplished. Preventing a considerable proportion of adults from being compromised by chronic heart disease will contribute to the health of the population, and thus a more productive adult work force. Even if price of diagnosis is not an issue for a government, acceptance of public health reform for heart disease by the population may be advanced by the combined leadership of legislators and distinguished stakeholders today. 


\section{Financial Support}

The authors received no external funding support for this manuscript.

\section{Acknowledgements}

We thank the following individuals for their efforts and assistance in having New Mexico State legislative bill \#126 become law in 2020. David Scrace MD, Cabinet Secretary, Human Services Department, Russell Taol, Superintendent of Insurance, State of New Mexico, Michael Burkhart, former Secretary Dept of Health, State of New Mexico, Rep Liz Thomson, New Mexico House of Representatives, Rep Debra Armstrong, New Mexico House of Representatives, Michael Padilla, Senator New Mexico State Senate, Jerry Ortiz y Pino, Senator New Mexico State Senate, Michael Padilla, Senator New Mexico State Senate, Gaye Kernan, Senator New Mexico State Senate, Martin Hickey MD, Senator New Mexico State Senate, Scott Obenshain MD, Pediatrician University of New Mexico HSC, and Barry Ramo MD. Professor of Cardiology, University of New Mexico HSC.

\section{Conflicts of Interest}

The authors declare no conflicts of interest regarding the publication of this paper.

\section{References}

[1] Hecht, H.S. (2015) Coronary Artery Calcium Scanning, Past, Present, Future. JACC: Cardiovascular Imaging, 8, 579-596. https://doi.org/10.1016/j.jcmg.2015.02.006

[2] Schade, D.S. and Eaton, R.P. (2019) A Simplified Approach to Reducing Cardiovascular Risk. The Journal of Clinical Endocrinology \& Metabolism, 104, 6003-6039. https://doi.org/10.1210/jc.2018-02509

[3] Adner, R. (2017) Ecosystem as Structure: An Actionable Construct for Strategy. Journal of Management, 43, 39-58. https://doi.org/10.1177/0149206316678451

[4] Adner, R. and Zemsky, P. (2005) Disruptive Technologies and the Emergence of Competition. Rand Journal of Economics, 36, 229-254.

[5] Maron, D.J., Hochman, J.S., Reynolds, H.R., et al. (2020) Initial Invasive or Conservative Strategy for Stable Coronary Disease. The New England Journal of Medicine, 382, 1395-1407. https://doi.org/10.1056/NEJMoa1915922

[6] American Heart Association CVD Burden Report. Cardiovascular Disease: A Costly Burden for America Projections through 2035.

https://www.heart.org/-/media/files/get-involved/advocacy/burden-report-consume r-report.pdf?la=en

[7] National Association of Chronic Disease Directors, and Centers for Disease Control and Prevention. Coronary Heart Disease, Myocardial Infarction, and Stroke-A Public Health Issue.

https://www.cdc.gov/aging/agingdata/docs/Coronary-Stroke-Brief-508.pdf

[8] Blaha, M.J., Blumenthal, R.S., Budoff, M.J. and Nasir, K. (2011) Understanding the Utility of Zero Coronary Calcium as a Prognostic Test: A Bayesian Approach. Circulation: Cardiovascular Quality and Outcomes, 4, 253-256. 
https://doi.org/10.1161/CIRCOUTCOMES.110.958496

[9] Greenland, P. (2015) When Nothing Is Really Something: New Evidence of the Importance of Zero Coronary Calcium. JACC: Cardiovascular Imaging, 8, 910-912. https://doi.org/10.1016/j.jcmg.2015.02.028

[10] Budoff, M.J., Young, R., Burke, G., et al. (2018) Ten-Year Association of Coronary Artery Calcium with Atherosclerotic Cardiovascular Disease (ASCVD) Events: The Multi-Ethnic Study of Atherosclerosis (MESA). European Heart Journal, 39, 2401-2408. https://doi.org/10.1093/eurheartj/ehy217

[11] Arnett, D.K., Blumenthal, R.S., Albert, M.A., Buroker, A.B., et al. (2019) 2019 ACC/AHA Guidelines on the Primary Prevention of Cardiovascular Disease: A Report of the American College of Cardiology/American Heart Association Task Force on Clinical Practice Guidelines. Circulation, 140, e596-e646.

https://doi.org/10.1161/CIR.0000000000000725

[12] Piepoli, M.F., Hoes, A.W., Agewall, S., et al. (2016) European Guidelines on Cardiovascular Disease Prevention in Clinical Practice. European Heart Journal, 37, 2315-2381.

[13] Eaton, R.P., Burge, M.R., Comerci, G., Cavanaugh, B., Ramo, B. and Schade, D.S. (2016) Abnormal Coronary Artery Calcium Scans in Asymptomatic Patients. The American Journal of Medicine, 130, 394-397. https://doi.org/10.1016/j.amjmed.2016.10.006

[14] Naghavi, M., Maron, D.J., Kloner, R.A., Berman, D.S., Budoff, M., Superko, H.R. and Shah, P.K. (2019) Coronary Artery Calcium Testing: A Call for Universal Coverage. Preventive Medicine Reports, 15, Article ID: 100879.

https://doi.org/10.1016/j.pmedr.2019.100879

[15] America's Health Rankings Analysis of America's Health Rankings Composite Measure, United Health Foundation.

https://www.americashealthrankings.org/explore/annual/measure/Overall a/state/T $\underline{\mathrm{X}}$

[16] Doherty, B.A., Cooney, T.G., Mire, R.D., Engel, L.S., Goldman, J.M., Health and Public Policy Committee and Medical Practice and Quality Committee of the American College of Physicians (2020) Envisioning a Better U.S. Health Care System for All: A Call to Action by the American College of Physicians. Annals of Internal Medicine, 172, S3-S6. https://doi.org/10.7326/M19-2411

[17] Spertus, J.A., Jones, P.G., Maron, D.J., et al. (2020) Health-Status Outcomes with Invasive or Conservative Care in Coronary Disease. The New England Journal of Medicine, 382, 1408-1419. https://doi.org/10.1056/NEJMoa1916370 